Original Research Article

\title{
Splenomegaly in malaria patients in a tertiary care institute: A study from central India
}

\author{
Soni P. ${ }^{1}$, Jalaly T. $^{2}$ \\ ${ }^{1}$ Dr. Pradip Soni, Associate Professor, ${ }^{2}$ Dr. Tariq Jalaly, Professor, both authors are affiliated with Department of \\ Medicine, Chirayu Medical College and Hospital Bhopal, M.P. India.
}

Corresponding Author: Dr. Tariq Jalaly, Professor, Department of Medicine, Chirayu Medical College and Hospital Bhopal, M.P. India. Email: tariqjalaly@gmail.com

\begin{abstract}
Introduction: The spleen is always affected in person suffered from malaria. The palpable spleen is one of the main clinical symptoms. History of fever, anemia and splenomegaly are predicting symptoms for clinical diagnosis of malaria infection in endemic area. Material and Methods: The study was conducted in the department of Medicine, Chirayu medical college and hospital Bhopal. All patients of age equal or greater than 15 years presenting with the fever and had positive peripheral smear for malaria parasite were included in my study. Results: $81 \%(n=21)$ patients of asexual stage had enlarged spleen where as $19 \%(n=5)$ patients of sexual stage had enlarge spleen. There is significant association of splenomegaly with asexual stage. All cases have splenomegaly in mixed species, $41.60 \%(n=20)$ splenomegaly seen in P. falciparum species and only $20 \%$ splenomegaly seen in P. vivax species. Conclusion: Though clinical examination is one of the good method to detect splenomegaly USG examination is superior as its sensitivity and specificity is higher than clinical examination. Hence it is recommended that splenomegaly be detected by USG examination in cases of malaria.
\end{abstract}

Keywords: Splenomegaly, Malaria, P. Falciparum, P. vivax

\section{Introduction}

Spleen has an important role in defense mechanism against malarial infection. As the body's largest lymphoid organ, the spleen has a variety of immunologic functions including as a sieve for the blood removing blood cells, microorganisms, and immune complexes.

The spleen was always affected in person suffered from malaria. The palpable spleen is one of the main clinical symptoms. History of fever, anemia and splenomegaly are predicting symptoms for clinical diagnosis of malaria infection in endemic area [1].

The spleen enlargement in an individual occurs if he experiences parasitemia for a period exceeding two weeks. There after the degree of spleen enlargement depends upon the duration of exposure and severity of parasitemia [2]. As the endemicity increases, the average enlargement of the spleen is considered to be greater. Some renowned malariologists have even

Manuscript received: $16^{\text {th }}$ February 2018

Reviewed: $26^{\text {th }}$ February 2018

Author Corrected: $5^{\text {th }}$ March 2018

Accepted for Publication: $12^{\text {th }}$ March 2018 considered spleen examination superior to the blood examination. Splenomegaly thus becomes extremely important in reaching a diagnosis in all cases of questionable malaria, especially the ones presenting atypically [3].

The objective of this study was to find out the relationship between Splenomegaly and malaria patients attending OPD of medicine department of Chirayu Medical College and Hospital, Bhopal, M.P.

\section{Material and Methods}

It was a cross sectional study, patients were selected from Medicine OPD and indoor wards of Department of Medicine, Chirayu Medical College and Hospital Bhopal. All patients of age equal or greater than 15 years presenting with the fever and had positive peripheral smear for malaria parasite were included in my study.

All the patients who had fever and splenomegaly due to other tropical disease were excluded from the study. 
Procedure: Each case was subjected to detailed interrogation and through clinical, including personal history. Thick and thin film were prepared and stained by JSB staining. Ultra-sonography was done by Shimadzu (SOU-500) and L \& T selectra machine with

\section{Results}

Table No.-1: Age wise distribution of splenomegaly.

\begin{tabular}{|c|c|c|c|c|}
\hline \multirow{2}{*}{ Age Group } & \multicolumn{3}{|c|}{ USG Examination } & \multirow{2}{*}{ Total } \\
\cline { 2 - 5 } & Normal & Enlarged & \% & 41 \\
\hline $15-20$ & 23 & 18 & 69.24 & 15 \\
\hline $31-40$ & 8 & 7 & 26.92 & 7 \\
\hline $41-50$ & 7 & 0 & 0 & 4 \\
\hline $61-60$ & 4 & 0 & 0 & 3 \\
\hline $61-70$ & 2 & 1 & 3.84 & $\mathbf{7 0}$ \\
\hline
\end{tabular}

$\chi 2$ test $=7.10, \quad \mathrm{p}=0.008$

This table shows maximum no. of enlarged spleen found in group $15-30$ years $69.24 \%$ ( $\mathrm{n}=41$ ). No enlarged spleen is found in 41-60 years age group of patients. There is a significant decreasing trend of splenomegaly in older age group.

Table No.-2: Malaria parasite: stage wise distribution of splenomegaly.

\begin{tabular}{|c|c|c|c|}
\hline \multirow{2}{*}{ Species } & \multicolumn{2}{|c|}{ Spleen Enlarge } & \multirow{2}{*}{ Total } \\
\cline { 2 - 4 } & Asexual Stage & Sexual Stage & 43 \\
\hline Mixed & 1 & 3 & 27 \\
\hline PV & 17 & 1 & 70 \\
\hline PV & 3 & $\mathbf{5}$ & $\mathbf{2 6}$ \\
\hline Total & $\mathbf{2 1}$ & $\mathbf{1 9}$ & $\mathbf{1 0 0}$ \\
\hline
\end{tabular}

$\chi 2$ test $=4.19, \quad \mathrm{p}=0.00001$

This table shows $81 \%(n=21)$ patients of asexual stage had enlarged spleen where as $19 \%(n=5)$ patients of sexual stage had enlarge spleen. There is significant association of splenomegaly with asexual stage.

Table No.-3: Malaria parasite species age wise distribution of splenomegaly.

\begin{tabular}{|c|c|c|c|c|}
\hline \multirow{2}{*}{ MP Species } & \multicolumn{3}{|c|}{ USG Examination } & \multirow{2}{*}{ Total } \\
\cline { 2 - 5 } & Normal & Enlarged & $\%$ & 2 \\
\hline Mixed & 0 & 2 & 100 & 48 \\
\hline PF & 28 & 20 & 41.66 & 20 \\
\hline PV & 16 & 4 & 20 & 20 \\
\hline
\end{tabular}

This table shows that all cases of mixed species has splenomegaly, $41.60 \%(n=20)$ splenomegaly seen in P. falciparum species and only $20 \%$ splenomegaly seen in P. vivax species. 


\section{Discussion}

In the present study, the maximum number of patients having splenomegaly is $69.24 \%$ in the $15-30$ years age group. A significantly decreasing trend of splenomegaly in older age group was found.

Size of splenic enlargement in children after the age of 8 to 10 years is affected by development of immunity which reduces parasite density in the peripheral blood and in holoendemic area adult do not show splenic enlargement. ${ }^{3}$ Sanjib Mohanty et al also found in their study that splenomegaly occurred more frequently in children $76 \% \mathrm{v} / \mathrm{s} 61 \%$ in adult. So, this study supports our study [4].

In the present study splenomegaly was found mostly ( $81 \%$ patients) in asexual stage (acute infection) of malaria parasite, while only $19 \%$ patients with splenomegaly had sexual stage. So there is a significant co-relation of splenomegaly with asexual stage. This may be due to the fact that most of our patients had $\mathrm{P}$ falciparum infection. In $\mathrm{P}$ falciparum infection heavy parasitemia is more common, so increased clearance of parasitized and non-parasitized erythrocytes occurs in the presence of splenomegaly [5].

White MS et al in 1986 have reported splenomegaly in $53 \%$ cases of acute attack of uncomplicated malaria [6].

In present study $100 \%$ patients of mixed species infection had splenomegaly. In P falciparum infection $41.66 \%$ patients and in $\mathrm{P}$ vivax infection $20 \%$ patients had splenomegaly. So splenomegaly is probably more common in mixed infection than isolated infection.

D. R. Ohalohan also found splenomegaly in $33 \%$ patients in mixed infection, $16 \%$ in $\mathrm{P}$, falciparum infection and $9 \%$ in $\mathrm{P}$ vivax infection in their study [7]. Strickland GT at al found in their study that larger the spleen more likely a P. falciparum infection, whereas $P$ vivax was more commonly associated with minimal spleen enlargement [8]. Hazra BR et al found splenomegaly in $40 \%$ cases with $\mathrm{P}$ falciparum infection and only in $18,18 \%$ cases of $\mathrm{P}$ vivax infection [9].

Generally, spleen enlarges more in P. falciparum infection due to phagocytosis of parasitized RBC and their accumulation in spleen for clearance. We observed splenomegaly in $41 \%$ of $\mathrm{P}$. falciparum and $20 \%$ of $\mathrm{P}$. vivax patients. An almost similar enlargement of around $39-45 \%$ was observed P. falciparum patients of Saudi Arabia $[10,11]$. However, much higher rate of splenomegaly $(71 \%)$ was recorded in falciparum malaria from the other parts of India [12]. This change might be due to differences in the immune status of patients from different malaria transmission regions.

\section{Conclusion}

There are various parameters in the clinical examination; of which splenomegaly is one of them and this is directly related with severity of malaria. Though clinical examination is one of the good method to detect splenomegaly USG examination is superior as its sensitivity and specificity is higher than clinical examination. Hence it is recommended that splenomegaly be detected by USG examination in cases of malaria. To prevent further complications in malaria, it is suggested that both $\mathrm{P}$. falciparum and P. vivax infections must be treated with the most effective antimalarials, preferably combined therapy aiming at different biochemical targets.

\section{Funding: Nil, Conflict of interest: None Permission of IRB: Yes}

\section{References}

1. Bruce-Chwatt LJ. Essential Malariology, 2nd ed. London, William Heinemann Medical Books Ltd, 1978:72-8.

2. Sharma RS, Sharma GK, Dhillon G.P.S., Measurement of malaria. Epidemiology \& control of malaria in India NPEM 1998; Govt of India, Ministry of Health \& Family Welfare, National Malaria Eradication Programme, Directorate General of Health Services, Delhi 54; 101-117.

3. Mashaal HAH. Splenomegaly in Malaria. Ind $\mathbf{J}$ Malariol 1986; 23:1-18.

4. Mohanty S., Saroj K., Mishra SP, Jayakrushna P., Bhabani SD. Complications and mortality patterns due to Plasmodium falciparum malaria in hospitalized adults and children, Orissa, India. Trans. R Soc. Trop, Med. Hyg. (2003).

5. Looareesuwan S, et al. 1987 Dynamic alteration in splenic function during Acute falciparum malaria $\mathrm{N}$ Engl J Med 317:675-679.

6. White NJ, Warrell DA, Chanthavanich $P$, et al. Severe hypoglycemia and hyperinsulinemia in falciparum malaria. N Engl J Med 1983, 309:61-66. 
Original Research Article

7. O'Holohan D.R. Clinical and laboratory presentation of malaria: An analysis of one thousand subjects with malaria parasitaemra. The J. of Trop Med Hyg, Sep. 1976;191-196.

8. Strickland GT, Fox E, Hadi H. Malaria and splenomegaly in the Punjab. Trans R Soc Trap Med Hyg. 1988;62(5):667-70.

9. Hazra BR, Chowdhury RS, Saha $\mathrm{SK}_{\mathrm{P}}$ Ghost MB, Mazumber AK. Changing scenario of malaria, a study at Calcutta. Indian J Malarial 1998 Jun;35 (2): 111-6.
10. Banzal S, Ayoola FA, El Sammani FE, Rahim SI, Subramanium P, Gadour MOE, Jain AK. The clinical pattern and complications of severe malaria in the Jazan region of Saudi Arabia. Ann Saudi Med. 1999; 1:378-380.

11. Malik GM, Seidi O, El-Taher AM, Mohammad AS. Clinical aspects of malaria in the Asir region, Saudi Arabia. Ann Saudi Med. 1998;18:15-17.

12. Kochar DK, Kaswan K, Kochar SK, Sirohi P, Pal M, Kochar A, Agrawal RP, Das A. A comparative study of regression of jaundice in patients of malaria and acute viral hepatitis. J Vector Borne Dis. 2006; 43: 123-129.

\section{How to cite this article?}

Soni P, Jalaly T. Splenomegaly in malaria patients in a tertiary care institute: A study from central India. Int J Med Res Rev 2018;6 (03):182-185. doi:10.17511/ijmrr. 2018.i03.08. 